\title{
Comparison of results of endovascular stenting and bypass grafting for TransAtlantic Inter-Society (TASC II) type $B, C$ and D iliac occlusive disease
}

\author{
Rimantas Benetis ${ }^{1}$, Zana Kavaliauskiene ${ }^{2}$, Aleksandras Antusevas², Rytis Stasys Kaupas ${ }^{3}$, \\ Donatas Inciura², Sarunas Kinduris ${ }^{1}$
}

\begin{abstract}
${ }^{1}$ Clinic of Cardiac, Thoracic and Vascular Surgery, Medical Academy, Lithuanian University of Health Sciences, Lithuania; Institute of Cardiology, Medical Academy, Lithuanian University of Health Sciences, Kaunas, Lithuania

${ }^{2} \mathrm{Clinic}$ of Cardiothoracic and Vascular Surgery, Lithuanian University of Health Sciences, Kaunas, Lithuania

${ }^{3}$ Department of Radiology, Medical Academy, Lithuanian University of Health Sciences, Kaunas, Lithuania
\end{abstract}

Submitted: 11 May 2014

Accepted: 19 July 2014

Arch Med Sci 2016; 12, 2: 353-359

DOI: 10.5114 /aoms.2016.59261

Copyright (c) 2016 Termedia \& Banach

\section{Abstract}

Introduction: The priority use of endovascular techniques in the management of aortoiliac occlusive disease has increased in the last decade. The aim of the present article is to report 1- and 2-year results of iliac artery stenting (IAS) and aortoiliac grafting in the management of patients with TASC II type B, C and D iliac lesions and chronic limb ischaemia.

Material and methods: In this prospective, non-randomised, one-centre clinical study, iliac artery stents and vascular grafts used for the treatment of patients with symptomatic lesions in the iliac artery were evaluated. This study enrolled 2 groups: 54 patients in the stent group and 47 patient in the surgery group.

Results: The primary patency rates at 1 and 2 years were $83 \%$ and $79.9 \%$ after IAS and $97.1 \%$ and $97.1 \%$ after surgical reconstruction, respectively $(p=0.015)$. The assisted primary stent patency at 1 and 2 years was $87.9 \%$ and $78.2 \%$, respectively. The complication rate was $7.4 \%$ in the stent group and $6.3 \%$ in the surgery group. There was no perioperative mortality in either group.

Conclusions: Our results reveal that patients with severe aortoiliac occlusive disease (TASC II types B, C and D) can be treated with IAS or surgically with satisfactory results. Iliac artery stenting is associated with decreased primary patency compared with the surgery group. Iliac artery stenting should be considered with priority in elderly patients or in patients with severe comorbidities.

Key words: aortoiliac occlusive disease, aortoiliac stenting, aortoiliac grafting, outcomes, complications.

\section{Introduction}

Nowadays, percutaneous transluminal angioplasty (PTA) and stenting are the methods of choice for the treatment of iliac artery atherosclerotic lesions. Lesions in the aortoiliac segment have been categorised according to their localisation, extension and morphology (stenosis vs.

\author{
Corresponding author: \\ Zana Kavaliauskiene \\ Clinic of Cardiothoracic \\ and Vascular Surgery \\ Lithuanian University \\ of Health Sciences \\ Eiveniu g. 2 \\ 50009 Kaunas, Lithuania \\ Phone: +37068267883 \\ E-mail: zana.kavaliauskiene@ \\ gmail.com
}


occlusion), with implications for their treatment. According to the recommendations of the Inter-Society Consensus for the Management of Peripheral Arterial Disease (TASC II) document, endovascular therapy is the treatment of choice for type A lesions and surgery is the treatment of choice for type $D$ lesions [1]. Patients with type $B$ and $C$ lesions can be managed by either stenting or bypass surgery depending on the patient's medical comorbidities [1]. The new type of stents and the recent advances in endovascular techniques have led to an extension of the indications to more extensive aortoiliac occlusive disease, with satisfactory long-term results [2-4]. The authors reported 1 -year primary stent patency rates to be from $85 \%$ to $93 \%$ and 5 -year primary patency rates from $70 \%$ to $80.5 \%$ in TASC II type D lesions [5-7]. According to these results, endovascular treatment of iliac artery occlusion can be successfully performed in older patients with severe cardiac pathology as an alternative method to open surgery without vascular prosthesis implantation and the risk of graft infection. Moreover, the risks of surgery are significantly greater than the risks of endovascular treatment, not only in terms of mortality, but also in terms of major morbidity and delay in return to normal activities [1].

In previous studies, researchers compared results of aortoiliac stenting (AIS) and bypass grafting for TASC types C and D aortoiliac occlusive disease [8, 9]. It was observed that AIS was associated with decreased primary patency at 48 months and shorter hospital stay [8].

\section{Material and methods}

Between 15 April 2011 and 15 April 2013, 316 patients underwent angiography with a diagnosis of aortoiliac atherosclerotic disease. Of these, 101 consecutive patients underwent treatment of iliac artery occlusive disease stratified as TASC II type $B, C$ and D iliac lesions [1]. Among these, 62 iliac endovascular procedures (87 stents) were performed in 54 patients (stent group) and 47 direct aortoiliac bypass reconstructions were performed in 47 patients (surgery group). The patients in the stent group were included in the study if their stenotic or occlusive lesion of the iliac arteries was considered suitable for stenting and successful lesion passage was achieved. If recanalisation of an iliac artery was not possible, the patients were also subsequently treated by open surgery. The analyses excluded patients with TASC II type A lesions, abdominal aorta or iliac artery aneurysms and extra-anatomic bypasses. All the patients were prospectively evaluated for their early, 1- and 2 -year stent and vascular graft patency. The study protocol was approved by the local bioethics committee. All the patients had evidence of chronic limb ischaemia classified according to Rutherford. The patients' demographic data, procedural and lesion-specific factors, outcomes and complications were defined according to the criteria prepared and revised by the Ad Hoc Committee on Reporting Standards [10, 11].

The endovascular procedures were performed in the angiography suite under the control of Innova 350 (GE Medical Systems, USA) by an interventional radiologist. Under local anaesthesia, an ipsilateral or a contralateral approach with a 6-French introducer was used depending on the clinical situation. Perioperative anticoagulation with heparin $5000 \mathrm{IU}$ was performed.

Balloon-expandable (BE) stents (Visi-Pro, EV3 and SCUBA, Medtronic/Invatec) were used preferentially for more focal lesions and severely calcified lesions. Self-expandable stents (PROTEGE EverFlex, EV3; Absolute, Abbott; Misago, Terumo; MARIS PLUS, Medtronic/Invatec) were usually placed for a diseased long segment or when the contralateral approach for stenting was used. The length of lesions was categorized according to the criteria of the Society of Cardiovascular and Interventional Radiology (SCVIR) [12] and was classified into 3 categories: lesions of $3-5 \mathrm{~cm}$, lesions of $5-10 \mathrm{~cm}$, and lesions greater than $10 \mathrm{~cm}$ in length.

After stent implantation, aspirin (100 mg/day) and clopidogrel $(75 \mathrm{mg} /$ day) were prescribed for 6 months [13]. After 6 months, aspirin (100 mg/day) was recommended for life-long use.

Direct aortoiliac bypass operations were performed in an operating room under general anaesthesia via a transperitoneal approach and unilateral bypass procedures via a retroperitoneal approach under epidural anaesthesia. Collagen-coated woven polyester prostheses (Polythese R IC/ICT, Perouse medical) were used for all the bilateral aortoiliac surgical reconstructions, whereas polyester Vascutek Gelseal (Terumo) prostheses were usually used for unilateral bypass reconstructions. After synthetic vascular graft implantation, aspirin (100 mg per day) and clopidogrel (75 mg per day) were prescribed for 6 months. After stent or prosthesis implantations, the patients were followed up 1, 3, 6, 9 and 12 months during the first year and 6 months after. Follow-up was obtained in all the patients and was performed using Duplex ultrasound. The clinical assessment consisted of physical examination, symptomatic evaluation and ankle-brachial pressure index $(\mathrm{ABI})$ measurements. The indications for secondary interventions included clinical symptoms associated with a $>0.15$ increase in the $A B I$ or detection of stenosis $>50 \%$ by sonography. In these cases, computed tomography angiography or digital subtraction angiography was performed. 
The following data were identified for each limb: the location of the lesion (common iliac artery (CIA), external iliac artery (EIA) or both), EIA stenosis or occlusion that involves the origins of the internal iliac and/or common femoral artery (CFA), TASC II lesion types and the status of the ipsilateral superficial femoral artery (SFA) and the profunda femoris (PF) (patent, $>50 \%$ stenosis or occluded) [1]. Demographic data, patients' risk factors and all the independent predictors were statistically analysed and correlated with outcome. Iliac artery PTA and stent placement were considered technically successful if there was $<30 \%$ residual stenosis and the brachiofemoral pressure gradient was less than $5 \mathrm{~mm} \mathrm{Hg}$.

Primary and assisted primary patency for stents and prostheses were defined according to Rutherford et al. [11]. Haemodynamic success and clinical improvement were defined according to the Society for Vascular Surgery and the International Society for Cardiovascular Surgery reporting standards [11].

\section{Statistical analysis}

The statistical analysis was carried out with the software IBM SPSS Statistics 20 (IBM SPSS Inc., Chicago, IL). The quantitative data are presented as the mean and the standard deviation (SD) or as the mean standard error (SE). For testing the statistical hypothesis, the significance level of 0.05 was selected. For comparing the means of 2 groups, the independent samples $t$ test was used. For testing the statistical hypothesis about the independence of 2 variables, the $\chi^{2}$ test was used. All the analyses were performed according to the principle of intention-to-treat. Primary patency and assisted primary patency were determined with the Kaplan-Meier method, and the log-rank test was used to compare the results between the stent and surgery groups.

\section{Results}

In total, 54 patients (62 limbs) underwent iliac artery stenting IAS implantations (87 stents) and 47 patients (54 limbs) underwent aortoiliac surgical reconstruction. The patients undergoing IAS had a mean age of $67.9 \pm 9.9$ years, and the patients undergoing aortoiliac bypass were younger (63.2 \pm 9.5 years; $p=0.018$ ). Other demographic and clinical characteristics were similar in both groups (Table I).

The mean follow-up in the stent group was 15.4 months (range: 0.1-24.0) and was evaluated as 1-year and up to 2-year results. The number of lesions in each category was as follows: 13 lesions of $3-5 \mathrm{~cm}, 45$ lesions of $5-10 \mathrm{~cm}$ and 4 lesions of more than $10 \mathrm{~cm}$. Primary stenting was performed in $41(75.9 \%)$ patients. Elective stenting was performed for residual stenosis or pressure gradient after PTA in 9 (16.7\%) patients or dissection after balloon angioplasty in 4 (7.4\%) patients. Initial technical success was obtained in 62 procedures.

Single stents were used in $40(64.5 \%)$ lesions, 2 stents in 19 (30.6\%) lesions and 3 stents in $3(4.9 \%)$ lesions. Sixteen stents were placed in type B lesions (18.4\%), 50 stents in type C lesions (57.5\%) and 21 stents in type D lesions (24.1\%) (Table II).

The mean length of the stents was $59.6 \pm 19.9$ $\mathrm{mm}(\mathrm{SE}=2.7)$ (range: $27.0-120 \mathrm{~mm}$ ). Early stent thrombosis in $\leq 30$ days was detected in 2 (3.7\%) patients. Thrombectomies using a Fogarty catheter were unsuccessful, and unilateral iliofemoral bypass (IFB) was performed in both cases. After stent implantation, 14 additional concomitant surgical procedures were performed: 5 common femoral artery endarterectomies, 7 infrainguinal bypass procedures and 2 femoral profundoplasties due to EIA occlusion that involves the origins of the CFA and/or the PF.

Most often surgical reconstruction procedures were performed to treat unilateral disease: 24 (44.4\%) patients underwent IFB grafting and 16 (29.7\%) patients underwent unilateral aortofemoral grafting. Seven aortobifemoral bypass (ABF) grafting procedures (25.9\%) were performed to treat bilateral disease.

Simultaneous CFA endarterectomy was necessary in 6 patients, and femoral profundoplasty was required in 3 patients. The clinical follow-up was available in 47 patients in the surgery group. The mean follow-up was 15.6 months (range: 3.0-24.0). The $A B I$ significantly increased in both groups of patients. In the IAS group, the $A B \mid$ increased following intervention from $0.34 \pm 0.08$ to $0.81 \pm 0.14$ ( $p<0.001)$. In the surgery group, the $A B I$ increased following the operation from 0.35 \pm 0.07 to $0.84 \pm 0.14(p<0.001)$.

Improvement of subjective symptoms was also observed in all the patients of the stent and the surgery groups. Iliac occlusive disease was more extensive and multifocal in the surgery group, with more TASC II type D lesions; however, in the stent group, there were more TASC II type C lesions, with a prevalence of iliac artery stenosis (Table II).

The cumulative primary stent patency at 1 and 2 years was $83.0 \pm 5.2 \%$ and $79.9 \pm 5.8 \%$, respectively. The cumulative primary prosthesis patency at 1 and 2 years was $97.1 \pm 2.9 \%$ and $97.1 \pm 2.9 \%$, respectively (Figure 1 ).

The primary patency did not vary significantly with respect to TASC $\|$ stratification and ranged from $84.6 \pm 1.0 \%$ (type B) to $76.9 \pm 1.2 \%$ (type D) at 24 months (Figure 2).

During the follow-up, 5 patients died: 4 patients (after 4, 10, 12.5 and 12.5 months) due to 
Table I. Clinical characteristics of patient groups

\begin{tabular}{|c|c|c|c|}
\hline \multirow[t]{2}{*}{ Variable } & $\begin{array}{l}\text { Stent group } \\
\qquad(n=54)\end{array}$ & $\begin{array}{l}\text { Surgery group } \\
\quad(n=47)\end{array}$ & \multirow[t]{2}{*}{$P$-value } \\
\hline & $n(\%)$ & $n(\%)$ & \\
\hline \multicolumn{4}{|l|}{ Gender: } \\
\hline Male & $49(90.7)$ & $45(95.7)$ & 0.323 \\
\hline Female & $5(9.3)$ & $2(4.3)$ & \\
\hline \multicolumn{4}{|l|}{ Age [years]: } \\
\hline Mean (SD) & $67.9(9.9)$ & $63.2(9.5)$ & 0.018 \\
\hline$<70$ & $30(55.6)$ & $34(72.3)$ & \\
\hline$\geq 70$ & $24(44.4)$ & $13(27.7)$ & \\
\hline \multicolumn{4}{|l|}{ Smoking: } \\
\hline Smoke & $23(42.6)$ & $27(57.4)$ & \\
\hline Do not smoke & $20(37.0)$ & $10(21.3)$ & $\chi^{2}=3.231 ; \mathrm{d} f=2 ; p=0.199$ \\
\hline Quit smoking & $11(20.4)$ & $10(21.3)$ & \\
\hline \multicolumn{4}{|l|}{ Hypertension: } \\
\hline No & $20(37.0)$ & $13(27.7)$ & 0.316 \\
\hline Yes & $34(63.0)$ & $34(72.3)$ & \\
\hline \multicolumn{4}{|l|}{ Diabetes: } \\
\hline No & $52(96.3)$ & $47(100)$ & 0.497 \\
\hline Yes & $2(3.7)$ & 0 & \\
\hline COPD & $4(7.4)$ & $3(6.4)$ & 0.230 \\
\hline Coronary artery disease & $34(63)$ & $22(46)$ & 0.247 \\
\hline Chronic renal failure & $4(7.4)$ & $2(4.2)$ & 0.325 \\
\hline \multicolumn{4}{|l|}{ Symptoms: } \\
\hline Claudication: & $33(61.1)$ & $26(55.3)$ & \\
\hline Rutherford category 2 & $14(25.9)$ & $14(29.8)$ & \\
\hline Rutherford category 3 & $19(35.2)$ & $12(25.5)$ & \\
\hline Rest pain: Rutherford category 4 & $12(22.2)$ & $14(29.8)$ & $\chi^{2}=0.753, \mathrm{~d} f=2 ; p=0.686$ \\
\hline Gangrene: Rutherford category 5 & $9(16.7)$ & $7(14.9)$ & \\
\hline Mean hospital stay, mean (SD) [days] & $1.0(0.35)$ & $7.0(1.0)$ & $<0.001$ \\
\hline
\end{tabular}

COPD - chronic obstructive pulmonary disease.

myocardial infarction (MI) and 1 patient (after 13 months) following implantation due to colon carcinoma. Two (4.3\%) patients died after 14 and 19 months due to $\mathrm{Ml}$ in the surgery group; both patients were older than 70 years. In 3 (5.5\%) patients, in-stent restenosis (> 50\%) was detected at 9, 18 and 18 months: 1 in a TASC $\| \mathrm{C}$ lesion and 2 in a TASC II D lesion. These stenoses were successfully corrected by PTA. The assisted primary stent patency at 1 and 2 years was 87.9 $\pm 4.6 \%$ and $78.2 \pm 6.7 \%$, respectively. The assisted primary patency rates of the surgery group at
1 and 2 years were $97.1 \pm 2.9 \%$ and $93.3 \pm 4.6 \%$, respectively (Figure 3 ).

\section{Complications}

There was no perioperative mortality in either of the groups.

\section{Stent group}

There were $4(7.4 \%)$ stenting-related vascular complications, i.e. distal embolisations, which were corrected by embolectomy using a Fogarty catheter. 
Table II. Limb-based distribution, characteristics and procedural factors of 62 stenting (62 limbs treated) and 47 surgical procedures (54 limbs treated) for TASC II type B, C and D lesions

\begin{tabular}{|c|c|c|c|}
\hline Variable & $\begin{array}{c}\text { Stent group } \\
(n=62 \text { limbs }) \\
n(\%)\end{array}$ & $\begin{array}{c}\text { Surgery group } \\
(n=54 \text { limbs }) \\
n(\%)\end{array}$ & $P$-value \\
\hline \multicolumn{4}{|l|}{ Iliac artery disease: } \\
\hline Stenosis & $37(59.7)$ & $16(29.6)$ & $<0.001$ \\
\hline Occlusion & $25(40.3)$ & $38(70.4)$ & \\
\hline \multicolumn{4}{|l|}{ EIA involvement: } \\
\hline No & $19(30.6)$ & $9(16.7)$ & 0.079 \\
\hline Yes & $43(69.4)$ & $45(83.3)$ & \\
\hline \multicolumn{4}{|c|}{ TASC II stratification of iliac artery lesions: } \\
\hline$B$ & $13(21.0)^{*}$ & $2(3.7)^{*}$ & \multirow{2}{*}{$\begin{array}{c}\chi^{2}=20.205, \mathrm{~d} f=2 ; p<0.001 ; \\
p<0.05\end{array}$} \\
\hline $\mathrm{C}$ & $36(58.0)^{* *}$ & $20(37.0)^{\star \star}$ & \\
\hline $\mathrm{D}$ & $13(21.0)^{\star \star \star}$ & $32(59.3)^{\star \star \star}$ & \\
\hline \multicolumn{4}{|l|}{ Runoff of ipsilateral SFA: } \\
\hline Open & $27(43.5)$ & $34(63.0)$ & $\chi^{2}=5.228, \mathrm{~d} f=2 ; p=0.073$ \\
\hline Stenosed (50-99\%) & $7(11.3)$ & $2(3.7)$ & \\
\hline Occluded & $28(45.2)$ & $18(33.3)$ & \\
\hline \multicolumn{4}{|l|}{ Runoff of ipsilateral PF: } \\
\hline Open & $60(96.8)$ & $51(94.4)$ & 0.269 \\
\hline Stenosed (50-99\%) & $2(3.2)$ & $3(5.6)$ & \\
\hline Occluded & 0 & 0 & \\
\hline
\end{tabular}

EIA - external iliac artery, PF - profunda femoris artery, SFA - superficial femoral artery.

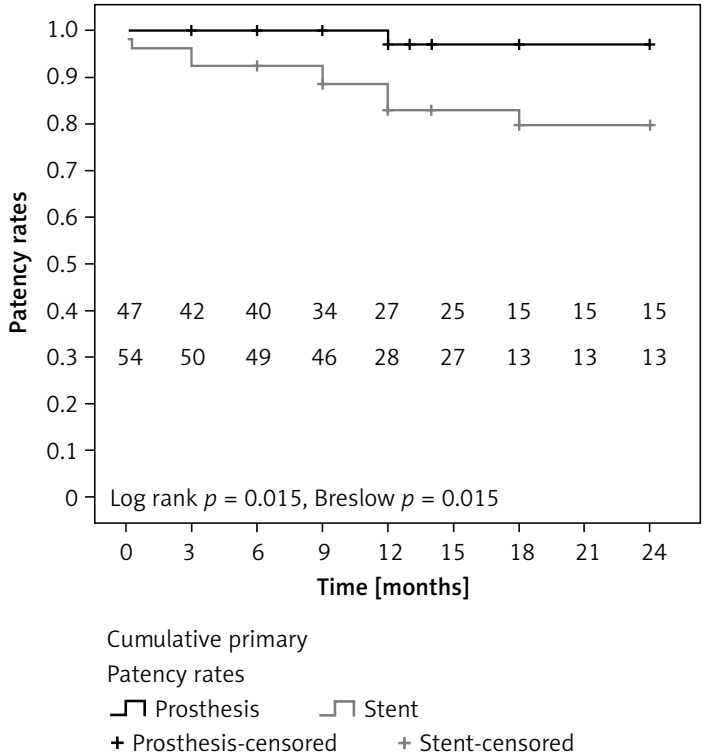

Figure 1. Kaplan-Meier curve estimates for the primary patency rates in the patients treated by aortoiliac grafting and stenting

These complications occurred in 3 of $41(7.3 \%)$ patients in the TASC II C/D group and in 1 of 13 (7.7\%) patients in the TASC II B group. The prevalence of complications was not significantly different between the TASC II C/D and TASC II B groups

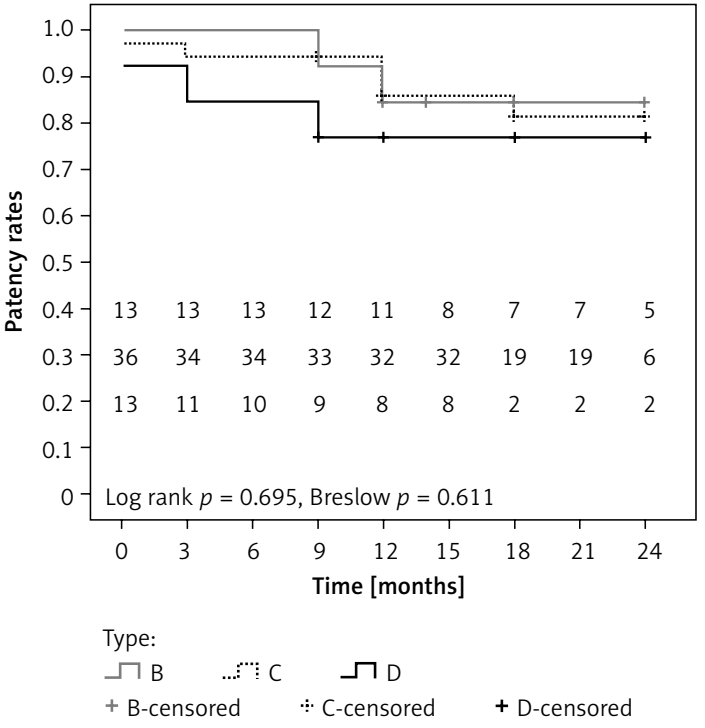

Figure 2. The limb-based Kaplan-Meier curve for the primary stent patency rates depending on the TASC II classification

$(p=0.8)$. Progression of infrainguinal occlusive disease was the cause of an above-the-knee amputation 7 and 14 months after iliac stenting in 2 patients. No stent infection was detected during the follow-up. 


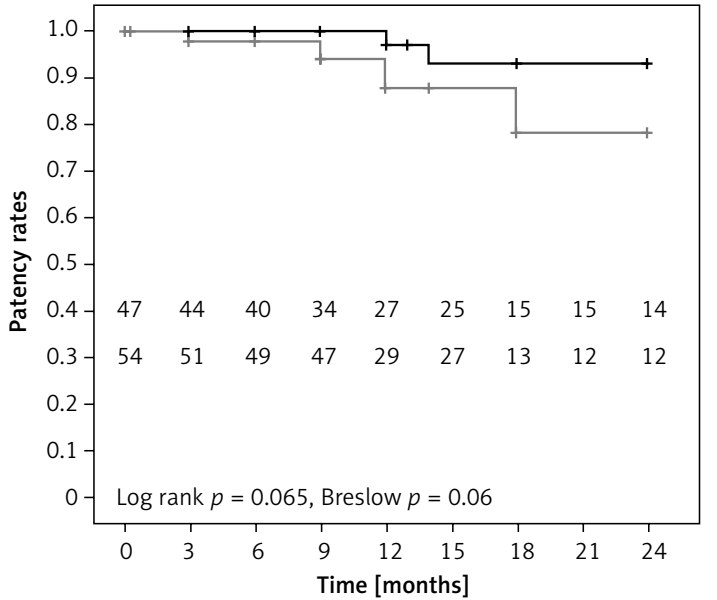

Cumulative assisted primary patency rates

$\neg$ Prosthesis $\quad \curvearrowleft$ Stent

+ Prosthesis-censored + Stent-censored

Figure 3. Kaplan-Meier analysis of the assisted primary patency rates in the patients treated by aortoiliac grafting and stenting

\section{Surgery group}

Complications occurred in 3 (6.3\%) patients. Postoperative complications presented as pneumonia in 1 (2.1\%) patient, and wound complications presented as hematoma in $1(2.1 \%)$ patient and inguinal lymphorrhoea in 1 (2.1\%) patient. All the patients were treated conservatively. During the follow-up in the surgery group, we detected 1 above-the-knee amputation 23 months after unilateral IFB. No graft infection was observed during the follow-up.

\section{Discussion}

Iliac artery PTA and stent placement are nowadays considered as alternative therapeutic options to open surgery for patients suffering from symptomatic aortoiliac occlusive disease. In our study, the primary patency rates after IAS at 1 and 2 years were $83.0 \%$ and $79.9 \%$, respectively. Our results are similar to those determined by Sixt et al. [5] and Kashyap et al. [14]: $86 \%$ and $82 \%$, respectively. However, Soga et al. [7] reported the primary iliac stent patency at 1 and 3 years to be $92.5 \%$ and $82.6 \%$, respectively. In the recent largescale prospective multicenter trial BRAVISSIMO, the authors revealed the primary stent patency rates at 12 months to be $93.1 \%$ for the total patient population treated for TASC A, B, C and D aortoiliac lesions [15].

In our study, the primary patency was lower in the IAS group; however, assisted primary patency in the IAS group was better but also lower in comparison with the surgery group. Other authors have reported similar results $[8,16]$.
In the present study, the primary stent patency at 1 and 2 years was $76.9 \%$ for TASC II type $D$ lesions. A number of researchers reveal 1-year primary stent patency rates to be from $85 \%$ to $93 \%$ and 5 -year primary patency rates from $70 \%$ to $80.5 \%$ after stenting of TASC II type D lesions $[5,6,7,15,17]$.

For both IAS and surgery groups, it is important to have adequate outflow. There were 14 patients in the IAS group and 9 patients in the surgery group who underwent reconstructions for concomitant infrainguinal disease. Timely intervention for the CFA and the SFA may have prevented stent or graft thrombosis $[8,18]$.

In our study, there were more unilateral surgical reconstructions compared with $\mathrm{ABF}(85.1 \%$ vs. $14.9 \%$ ), and iliac occlusive disease was more extensive and multifocal in the surgery group, with more TASC II type D lesions (59.3\% vs. $21.0 \%$; $p<0.05)$. No early mortality and no graft infection were observed in the surgery group, but this may be due to the small number of the patients in the ABF group (7 patients). Chiu et al. [19] performed a meta-analysis of 29 studies in 5,378 patients after ABF bypass: more than half of the patients were operated on for claudication. The operative mortality was $4.1 \%$, and major complications were present in $16 \%$ of the patients. The authors consider that there are no trials directly comparing outcomes after ABF and IFB. However, according to Zukauskas et al. [20], IFB is consistently reported as being less traumatic and requiring shorter exposure time when compared with ABF. The results of our study support this idea.

During the follow-up, 4 patients died due to $\mathrm{MI}$ in the stent group. However, no periprocedural myocardial ischaemia or MI was detected. These patients would have had a higher risk of open surgery. According to Flu et al. [21], the incidence of perioperative myocardial ischaemia following abdominal aorta surgery ranged from $14 \%$ to $47 \%$ and that of perioperative $\mathrm{MI}$ ranged from $1 \%$ to $26 \%$ (detected with troponin I or $\mathrm{T}$ measurements). Thus, vascular surgery patients are at an increased risk of developing perioperative cardiac complications. The results of our study show that patients with comorbidities should be treated by stenting with priority.

In our series, early iliac artery stent thrombosis ( $\leq 30$ days) was observed in $2(3.7 \%)$ patients. In both cases, the stent was placed in both iliac (CIA and EIA) arteries across the inguinal ligament and the patients had rest pain (category 4 according to the Rutherford classification). Ozkan et al. [6] reported early iliac artery stent thrombosis $(\leq 30$ days) in 8 of 118 (7\%) patients. The authors concluded that it was more likely associated with critical limb ischaemia than with intermittent claudication ( $50 \%$ vs. $4 \%$; $p=0.002$ ). 
The incidence of intraprocedural complications in the IAS group of $9.3 \%$ is similar to the reported incidence of $10 \%$ to $12 \%$ [8, 22]. According to Pulli et al. [3], there were $9 \%$ of perioperative complications following IAS in the iliac artery occlusion group and $3.5 \%$ in the iliac artery stenosis group. The majority of the intraprocedural complications of IAS can be managed conservatively. Early mortality following iliac stent implantation has been reported in several studies and ranged from $0.7 \%$ to $3.6 \%[2,4,23]$.

In conclusion, our results reveal that patients with severe aortoiliac occlusive disease (TASC II types B, C and D) can be treated with IAS or surgically with satisfactory results. The IAS is associated with decreased primary patency compared with the surgery group. The IAS should be considered with priority in elderly patients or in patients with severe comorbidities.

\section{Conflict of interest}

The authors declare no conflict of interest.

\section{References}

1. Norgren L, Hiatt WR, Dormandy JA, Nehler MR, Harris KA, Fowkes FG. Inter-Society Consensus for the Management of Peripherial Arterial Disease (TASC II). Eur J Vasc Endovasc Surg 2007; 45 Suppl S: S5-67.

2. Leville CD, Kashyap VS, Clair DG, et al. Endovascular management of iliac artery occlusions: extending treatment to TransAtlantic Inter-Society Consensus class C and D patients. J Vasc Surg 2006; 43: 32-9.

3. Pulli R, Dorigo W, Fargion A, et al. Early and long-term comparison of endovascular treatment of iliac artery occlusions and stenosis. J Vasc Surg 2011; 53: 92-8.

4. Jongkind V, Akkersdijk GJM, Yeung KK, Wisselink W. A systematic review of endovascular treatment of extensive aortoiliac occlusive disease. J Vasc Surg 2010; 52: 1376-83.

5. Sixt S, Alawied AK, Rastan A, et al. Acute and long-term outcome of endovascular therapy for aortoiliac occlusive lesions stratified according to the TASC classification: a single-center experience. J Endovasc Ther 2008; 15: 408-16.

6. Ozkan U, Oguzkurt L, Tercan F. Technique, complication, and long-term outcome for endovascular treatment of iliac artery occlusion. Cardiovasc Intervent Radiol 2010; 33: 18-24.

7. Soga Y, lida O, Kawasaki D, et al. Contemporary outcomes after endovascular treatment for aorto-iliac artery disease. Circ J 2012; 76: 2697-704.

8. Hans SS, DeSantis D, Siddiqui R, Khoury M. Results of endovascular therapy and aortobifemoral grafting for Transatlantic Inter-Society type C and D aortoiliac occlusive disease. Surgery 2008; 144: 583-90.

9. Timaran CH, Prault TL, Stevens SL, Freeman MB, Goldman $\mathrm{MH}$. lliac artery stenting versus surgical reconstruction for TASC (Trans Atlantic Inter-Society Consensus) type B and type C iliac lesions. J Vasc Surg 2003; 38: 272-8.

10. Ahn SS, Rutherford RB, Becker GJ, et al. Reporting standards for lower extremity arterial endovascular procedures. Society for Vascular Surgery/International Soci- ety for Cardiovascular Surgery. J Vasc Surg 1993; 17: 1103-7.

11. Rutherford RB, Baker JD, ERNST C, et al. Recommended standards for reports dealing with lower extremity ischaemia: revised version. J Vasc Surg 1997; 26: 517-38.

12. Guidelines for percutaneous transluminal angioplasty. Standards of Practice Committee of the Society of Cardiovascular and Interventional Radiology. Radiology 1990; 14: 619-29.

13. Aronow WS. Peripheral arterial disease of the lower extremities. Arch Med Sci 2012; 8: 375-88.

14. Kashyap VS, Pavkov ML, Bena JF, et al. The management of severe aortoiliac occlusive disease: endovascular therapy rivals open reconstruction. J Vasc Surg 2008; 48: 1451-7, 1457.e1-3.

15. Bosiers M, Deloose K, Callaert J, et al. BRAVISSIMO: 12-month results from a large scale prospective trial. J Cardiovasc Surg (Torino) 2013; 54: 235-53.

16. Sachwani GR, Hans SS, Khoury MD, et al. Results of iliac stenting and aortofemoral grafting for iliac artery occlusions. J Vasc Surg 2013; 57: 1030-7.

17. Park KB, Do YS, Kim DI, et al. The TransAtlantic InterSociety Consensus (TASC) classification system in iliac arterial stent placement: long-term patency and clinical limitations. J Vasc Interv Radiol 2007; 18: 193-201.

18. Chang RW, Goodney PP, Baek JH, Nolan BW, Rzucidlo EM, Powell RJ. Long-term results of combined common femoral endarterectomy and iliac stenting/stent grafting for occlusive disease. J Vasc Surg 2008; 48: 362-7.

19. Chiu KW, Davies RS, Nightingale PG, Bradbury AW, Adam DJ. Review of direct anatomical open surgical management of atherosclerotic aorto-iliac occlusive disease. Eur J Vasc Endovasc Surg 2010; 39: 460-71.

20. Zukauskas G, Ulevicius H, Janusauskas E. An optimal inflow procedure for multi-segmental occlusive arterial disease: ilio-femoral versus aorto-bifemoral bypass. Cardiovasc Surg 1998; 6: 250-5.

21. Flu WJ, Schouten O, van Kuijk JP, Poldermans D. Perioperative cardiac damage in vascular surgery patients. Eur J Vasc Endovasc Surg 2010; 40: 1-8.

22. Maurel B, Lancelevee J, Jacobi D, Bleuet F, Martinez R, Lermusiaux P. Endovascular treatment of external iliac artery stenoses for claudication with systematic stenting. Ann Vasc Surg 2009; 23: 722-8.

23. Kavaliauskienė Ž, Antuševas A, Kaupas RS, Aleksynas $N$. Recent advances in endovascular treatment of aortoiliac occlusive disease. Medicina (Kaunas) 2012; 48: 653-9. 